\title{
Numerical Study of Reinforced Concrete beam subjected to blast loading using Finite element package ABAQUS
}

\author{
Ann M Biju ${ }^{1}$, Athulya Sreesa E K ${ }^{2}$, Devika Remesh ${ }^{3}$, Rinsa K ${ }^{4}$, Anusree A ${ }^{5}$ \\ ${ }_{1,2,3,4}$ B Tech scholars, Department of civil engineering, MITS, India \\ ${ }^{5}$ Assistant professor, department of Civil engineering, MITS, India
}

\begin{abstract}
The threat of terrorism rising all over the world has increased the awareness among people. Efforts have been made to design structures which offers better resistance against blast explosion. Studies were conducted on the behaviour of structural members subjected to blast loads. In this study, the finite element package ABAQUS/Explicit was used to model a reinforced concrete beam, which was previously tested and reported in an experimental research paper the concrete damage plasticity approach was used to define the non-linearity of concrete. The effect of blast loading on the RC beam was analytically observed and deflection at mid-span of the beam was compared with the experimental results.
\end{abstract}

Keywords: ABAQUS, Blast, Concrete damage plasticity, Finite element method, Reinforced concrete beam.

\section{Introduction}

Explosion can be defined as the sudden release of energy within a very small duration. This will cause catastrophic damages to the building both externally and internally, which would even result in loss of life of the inhabitants. It is not possible to protect the structure from a direct hit by a nuclear bomb. But it is possible to design the structures when the point of explosion occurs at some distance away from the building. Immediately after the explosion, pressure waves are propagating through the atmosphere and it may be the cause for the damage of the structure. It is necessary to protect buildings like museum, stadiums, shopping centres etc and also buildings of high importance like embassies, public buildings etc.

Finite element method is a vast technique developed for the numerical solution of complex problems. Abaqus/CAE is a software based on the finite element method, which provides simple and consistent interface for creating, submitting, monitoring and evaluating results from Abaqus/Explicit simulations. The software has a number of modules, where each module defines a logical aspect of the modeling procedure. Abaqus/ CAE generates an input file that can submit to Abaqus/Explicit analysis product.

The experimental and numerical approaches are the two current analysis methods for RC beams under blast loading. Because of the preparation and measurement in full scale development, many experimental studies are not feasible. Beams are not designed for axial loads as it has negligible effects due to axial loading. Only lateral loading is only considered in the study. Experiments at reduced scales improve the engineering design. To estimate the damage levels and validate the scaling law of RC beams subjected to blast loadings few studies have been conducted. In this paper, evaluation of reinforced concrete beam subjected to blast loading was done using finite element method.

\section{Experimental Beam}

The data of the previous work by Zhang et al (2013) was used as experimental data. The RC beam B22 was used in the analysis. It has a square section with dimensions 100x100 mm. The overall length of the beam is $1100 \mathrm{~mm}$ and an effective cover of $25 \mathrm{~mm}$ is provided. The tensile, compressive and hoop reinforcement bar used in the test are all HPB 235 of $6 \mathrm{~mm}$ diameter. The uniaxial compressive strength of concrete is continued to be $40 \mathrm{MPa}$. The yield strength of reinforcement bars are $395 \mathrm{MPa}$ and $501 \mathrm{MPa}$.

The distribution of reinforcement bars are shown in the fig. 1. The beam was tested in the position shown in fig. 2.
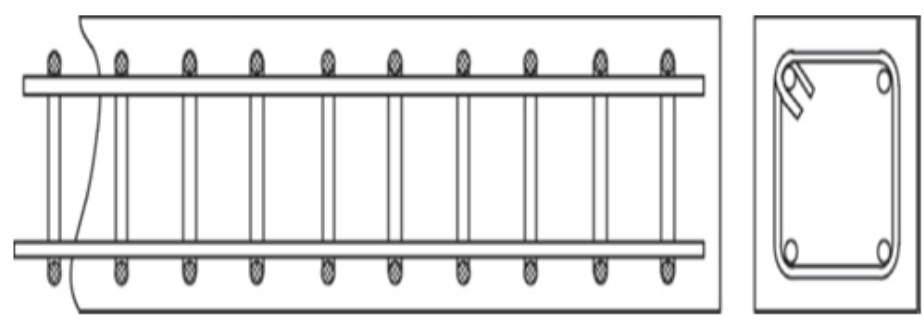

Figure 2.Distribution of reinforcement bars

(Source: Zhang et al,2013) 


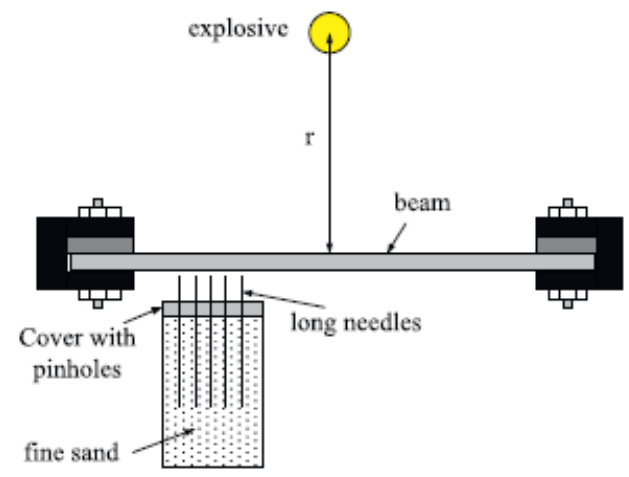

(Source: Zhang et al, 2013)

Figure 3.Illustration of test set-up

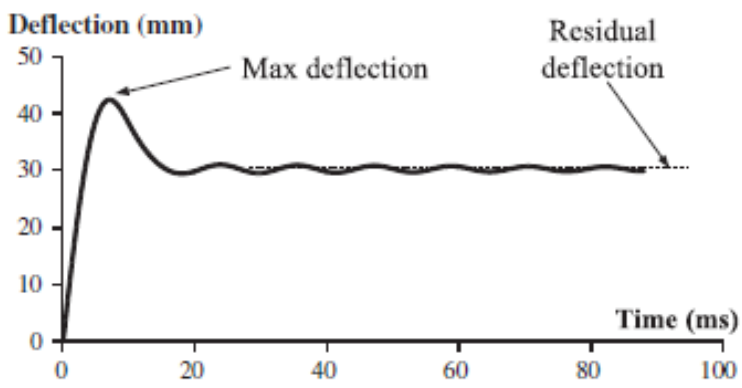

Figure 6. Curve between mid-span deflection of beam and time (Source: Zhang et al,2013)

\section{Material Non-Linearity}

Concrete damaged plasticity is one of the possible constitutive models to predict the behavior of concrete. It describes the constitutive behavior of concrete by introducing scalar damage variables. Tensile and compressive response of concrete can be characterized as shown in fig.3(a) and 3(b).

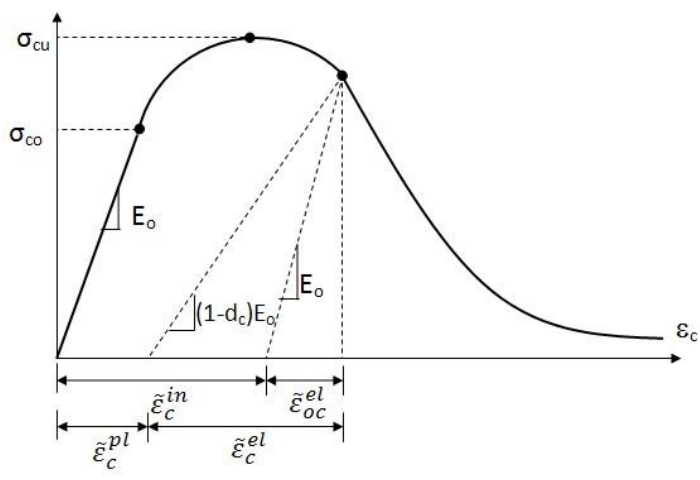

(a)

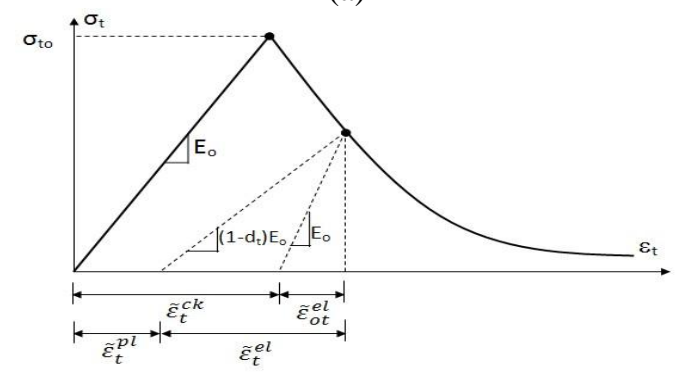

(b)

Fig. 3. Behaviour of concrete under uniaxial (a) compression and (b) tension.

(Source: Abaqus users manual, 2009) 
As shown in Fig. 3, the unloaded response of concrete specimen seems to be weakened because the elastic stiff- ness of the material appears to be damaged or degraded. The degradation of the elastic stiffness on the strain sof- tening branch of the stress-strain curve is characterized by two damage variables, $d t$ and $d c$, which can take values from zero to one. Zero represents the undamaged material where one represents total loss of strength. Plastic properties were assigned to the steel using idealized elastic-perfectly plastic curve for steel. Parameters specified are Elastic modulus, poison's ratio and yield strength.

\section{Finite Element Model}

The concrete body was modeled as a 3D deformable, solid part and both the steel rebars and stirrups were modeled as 3D deformable, wire part. All the parts were assembled maintaining an effective cover of $25 \mathrm{~mm}$ between concrete and steel. Interaction between steel and concrete was also specified.

\section{Loading and Boundary conditions}

Blast load was defined as air blast wave using the interaction module. TNT mass of $0.45 \mathrm{~kg}$ was applied at a stand-off distance of $0.4 \mathrm{~m}$. Scaled distance of $0.5 \mathrm{~m} / \mathrm{kg}^{1 / 3}$ was maintained. Created blast load was applied on the top surface of the beam. Fixed supports were given on both the ends of the beam.

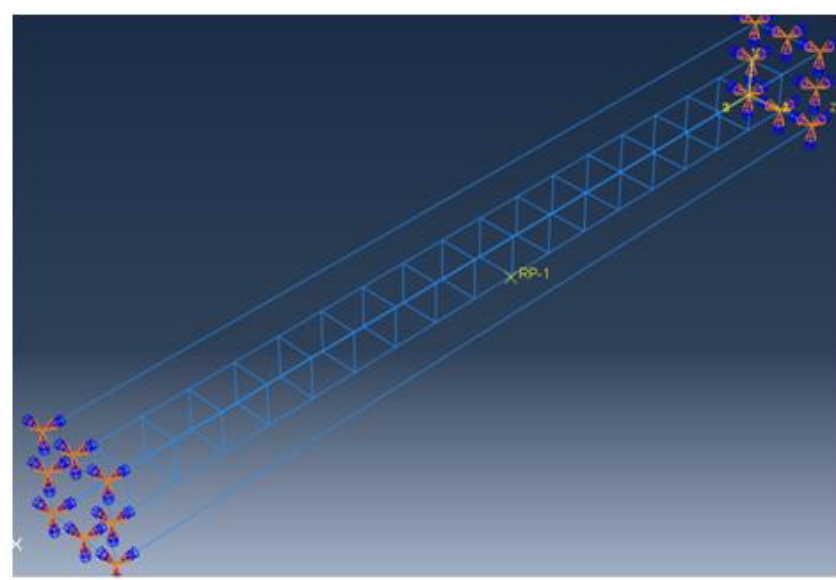

Fig 4. Loading and boundary conditions of the model

\section{The finite element mesh}

To getting accurate results from finite element analysis, same mesh was assigned to all the elements in the model so that each two different material share the same node. The structured type of mesh is selected in the model. The solid element has 8 nodes with 3 degrees of freedom at each node- translations in the nodal $\mathrm{x}, \mathrm{y}$ and $\mathrm{z}$ directions. The element is capable of plastic deformation, cracking in three orthogonal directions and crushing.

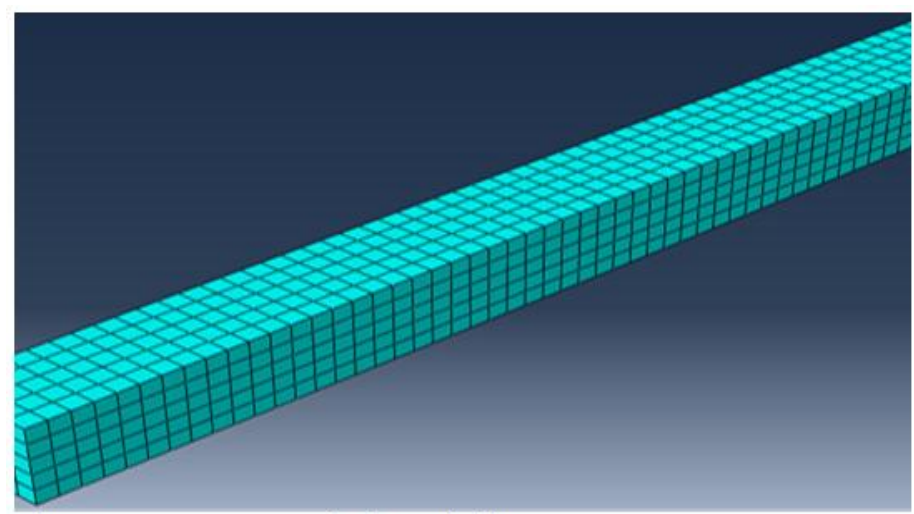

Figure 5 concrete meshed models in ABAQUS 


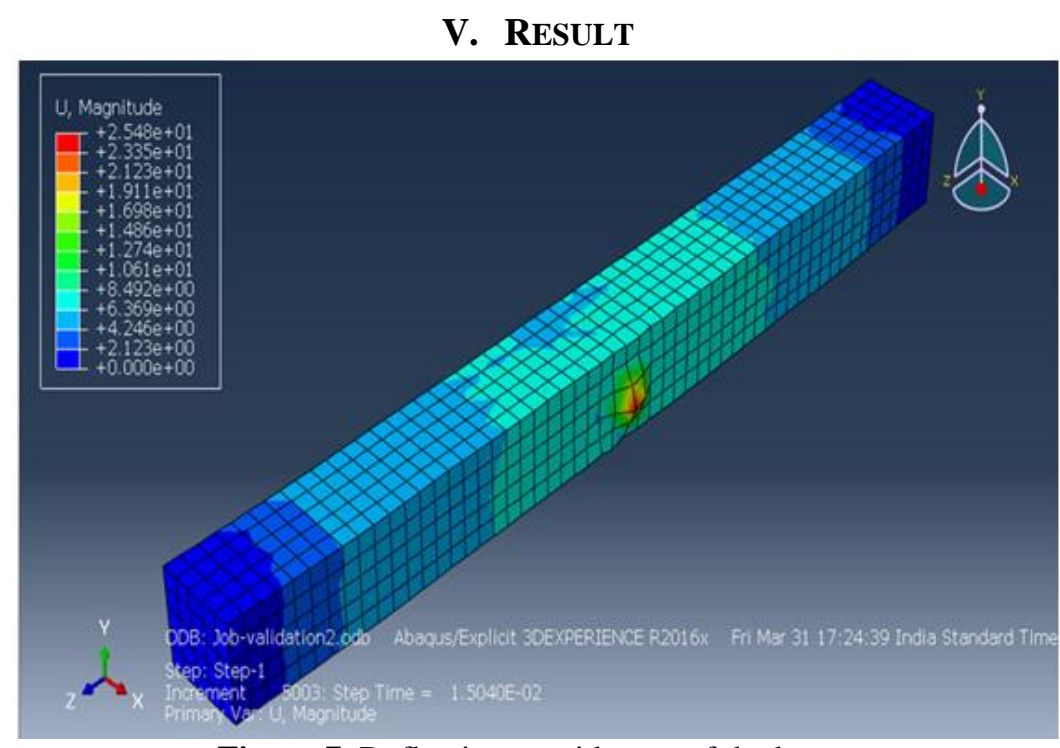

Figure 7. Deflection at mid-span of the beam.

In order to solve any type of Finite element problem, relevant job analysis should be established. After this, answer is visualized and compared with the experimental results.

A central residual deflection of $25.48 \mathrm{~mm}$ was obtained in the analysis. A residual deflection of $25 \mathrm{~mm}$ was obtained in the experimental study.

Variation in result $=25.48-25=0.48 \mathrm{~mm}$

Percentage $=(0.48 / 25) \times 100=1.92 \%$, which is a very low value.

Hence, validation is found to be acceptable.

\section{Conclusion}

The finite element model is validated using previous experimental results available in the literature. Numerical results were obtained with slight variation when compared with the experimental results for reinforced concrete beam subjected to blast loading

\section{Reference}

[1]. T. Krauthamar. (1990), "Response of reinforced concrete elements to severe impulsive loads", ASCE Journal.

[2]. Zhang, Yao, Lu, Chen, Lin, Wang, Yuliang, Lin (2013)," Experimental study on scaling of RC beams under close-in blast loading”, ELSEVIER.

[3]. F. A. Oluokun, E. G. Burdette, and J. H. Deatherage, "Splitting tensile strength and compressive strength relationships at early ages," ACI Materials Journal, vol. 88, no. 2, pp. 115-121, 1991

[4]. ACI 318-02. Building Code Requirements for Structural Concrete (ACI 318-02) and Commentary (ACI 318R-02). Farmington Hills, MI: ACI, 2002. Abaqus analysis user's manual(6.9)

[5]. S.V. Chaudhari and M. A Chakrabarti (2012), "Modeling of concrete for nonlinear analysis Using Finite Element Code ABAQUS", International Journal of Computer Applications Volume 44- No.7, April 2012 